\title{
On the Anti - Times of Features in Jia Baoyu's Characters of China's "Noble Son" from the Perspective of Psychology
}

\author{
Yingqun Wang, Pan Zhang, Xin Li, Ying Chen* \\ Changchun University of Technology, Changchun, Jilin, China \\ ${ }^{*}$ Corresponding Author: Ying Chen
}

Keywords: Three noble son; Jia Baoyu; character; anti-age.

\begin{abstract}
This article mainly discusses the relationship between the character and psychology of Jia Baoyu in the A Dream of Red Mansion in the first of four famous books of ancient China."Zhi Yanzhai in the review of A Dream of Red Mansions, in fact, has revealed the typical character of Jia Baoyu".This article sorts out the results of these studies which left by my predecessors, as ancient china's "noble son", Jia Baoyu is mischievous and disdains study, romantic and affectionate, antagonistic and abnormal in psychology, from these psychologicals to see his character on the anti-era.
\end{abstract}

\section{Introduction}

"The first task of psychology was to conduct Psychologists have generally regarded this observation as their data. Psychology research involves many areas such as perception, cognition, emotion, personality, behavior, interpersonal relationships, social relations, and education, art, literature, and many other aspects are closely linked."

\section{Mischievous and Disdains Study in Order to Shun the Secular World and Be High-Hearted}

Jao Baoyu is mischievous and disdains study."Cao Xueqin's purpose of the characters in description, just in order to charactaer personality, not only respect and depreciate him, but also suppress him because of the different heart, shaped outside, even the subtlest indoor furnishings, vary from it as well. "Li Chendong indicates that, because of thedifferences of life and psychological, the character is also different due to the difference. Jia Baoyu in Rongguo sites is the descendant of the descendants of their own, and his own smart and beautiful.But in the eyes of Jia Zheng, Baoyu is " truly incorrigible son"(the third chapter), "fiend in human shape".At the age of time to capture the "fat powder hairpin ring" move, it is provoked Jia Zheng,he was "not like"At the age of ten years old,Jia Baoyu is "abnormal naughty." Like Rong Guo Sitesin a noble family, naturally need a filial son to inherit ancestors, bring honour to the family name. As everyone knows, Baoyu's elders in the choice of Jia Baoyu, at the same time, somewhere for themselves and the family's highest interest in the choice of a dissident and destruction of power. He "likes to be free and miscellaneous collection" (the eight chapter), does not want to bear the responsibility. He is happy with ancient and modern fiction and legendary script, despise the "four books"(The Great Learning,The Doctrine of the Mean,The Confucian Analects,The Works of Mencius) and "five classics"(The Book of Songs,The Book of History,The Book of Changes,The Spring-Autumn Annals).The reason of both from the family background about sumptuous food and luxurious clothings, and the grandmother Jia spoiled Jia Baoyu, but also from the youth of the rebellious psychology - confined to adult rules, the lack of strong fame. Learning and excellent is the official, is the epitome of Confucian life.

Jia Baoyu shunes the secular world and be high-hearted. Jia Baoyu dream joyfully said: "This is interesting, I was here for a lifetime, even if the loss of home is willing' (chapter fifteen), Jia Baoyu deeply loved the ideal of the idealvirtual illusion. Running away from home is one of adolescents' most accustomed thoughts. The more confused the more able to reflect his subconscious or deep 
depressed real thoughts - this is his rebellious side, but also really have to show him on the Grand View outside the real world, adult world has a strong dissatisfaction and despise.

Freud said that this "father" image is the "original father" image. Jia Zheng tried to suppress the restoration of his father's image through force repression, this process is accompanied by blood and tears.He was beaten black and blue,but on his own choice of life is still no repentance.He despised the feudal forces of the family, anxious to find the pure land of the soul,hechosen to be a monk, his loneliness, his dissatisfactionfrom his psychological needs in the secular can not be achieved.He lamented that "no money can be used to fill the sky, in vain into the red if a few years" (the first chapter)[4]. Humanistic psychology believes that a person's cognitive development is leaping, triggering this cognitive development of the typical event is a "peak experience". People undergo the "peak experience", not only deepen the understanding of the self, but also a self-realization.This is not reminiscent of the master of the country, Ma Yifu, he was intelligent, the family mellow, like Western learning, but after returning to learn the Western Society for thirty years, "the fundamental reason for his pessimism on the current situation of the family and their own The situation of desolate loneliness for his pessimistic nature also caused a considerable impact,The film "Purgatory City" there is a refuge in the town, in the western United States pioneer period, there is the paradise, in the heart of Ma Yi and Jia Baoyu probably built for themselves such a "avoid the town".

\section{Universal Love and Compassion}

The results of modern psychology research show that the formation of a person's personality and its existence state must be influenced by his own innate and acquired factors such as the internal and external factors about physiology, psychology and society. There is no exception for Jia Baoyu. To the certain degree, A Dream of Red Mansionsmakes a revelation for the formation of Jia Baoyu's character.

He has a sensitive and fraternal heart. Although Baoyu is "a material that has not been used by the sky," once it has fallen to the ground, it becomes mortal and mortal, and as a result, there is no such thing as a mortal human being. In the sixth chapter, Baoyu and Xiren first sleeping together, it was not suitable according to moral standards at that time, Baoyu was a responsible man if he was married to a Xiren, in fact Baoyu just regarded Xiren as a "warm bed tool ",and he likes Qin Keqing, commended as "bright and charming, like the Bao Chai; romantic, another Dai yu", There is a love list in the eightieth chapter, JiaBaoyu's evaluation was "feeling and unfeeling",he had feelings not only to sentient beings, but also to the merciless objects. Baoyu was looking at Daiyu, smiling and saying: "I have seen this sister before". Jia Baoyu knew Qingwen likes to eat bean curd stuffed bun, no matter where he went to eat, as long as he saw this thing, he would say he wanted to keep it eating, and let people sent to him, in fact, all of it was to be given to Qingwen. And Qingwen teared fan, Baoyu left her alone when he saw Qingwen is happy with it, is this not a kind of love and preference? Baoyu remembered Xiren like eating cheese steamed with sugar, so he left it to her. He remembered clearly everyone's taste in this house. In the twentieth chapter Xiren was sick, lying in bed with fever, and when an old woman who did house work sent the fried medicine, Jia Baoyu witnessed a little sweat in Xiren's face, refused to let her up, and pillowed to her to drink the medicine. In addition to Jia Baoyu, it is estimated that other men could not do such things, who would have maid drinking medicine? Bao $\mathrm{Yu}$ strongly told girls: they are the purest and most translucent, he never treats them as humble servants. Jia Baoyu in the male-dominated society would not be allowed to be overly intimacy with his maidservant for identity and status, However, he had both sympathy and love for his daughterboth love and attachment, and emotion were complex. This feeling surpassed the rank of master and servant, crossed the secular boundaries, and offered consideration with heart and soul. He sympathized with his servants, loved them with heart; he was romantic, pursued the true love. All in all, Baoyu was a rebel who was against the the girls' unequal treatment and a baptism of master-servant thinking of the feudal aristocratic family, which is different from the love between him and Lin Daiyu. Even he could not walk for being beaten in the chapter of" Baoyu was beaten", the 
most immoral person in the his mind was "Lin Sister," said that he was pretend and let her do not worry about him, it strongly showed that he was not "obscenity", it was his anti-epoch character with great love and sympathy.

\section{Jia Baoyu is Rebellious But Never Fears Innovation}

"Traitorous psychology is a mental activity produced when objective environment is not consistent with subjective needs." The author Cao Xueqin took thirty five chapters (Chapter Eighteenth-Chapter Fifty two) to describe what happened when Jia Baoyu was thirteen years old, which was exactly rebellious period.

Jia Baoyu is rebellious and independently minded.Jia Baoyu's rebellion character was not stereotyped startly, and the work put forth effort to describe the history of development and growth of his character.In his life, the most important thing was undoubtedly falling love with Lin Daiyu.This kind of love,on the one hand,started from rebellious character,one the other hand,prompted the final form of his rebellious character.Jia Baoyu as well as Lin Daiyu was not only required freedom of marriage,but also they deviated from the way of life of feudal society.Jia Baoyu resisted the arrangement of his feudal family to the utmost, and chose his companion about future life independently.Jia Baoyu shouted in his dream,"'how do I believe what Monk and Taoist priest say!It isn't Gold and Jade Predestined Match,it's Wood Front.'(Chapter thirty six) Jia Baoyu deeply loved ideality in utopia a state of vision and emptiness. Running away from home was also one of the most habitual thoughts of the adolescents. Jia Baoyu deeply loves the ideal of an ideal country - the great void dreamland. The more dazed the consciousness was, the better it could reflect his subconsciousness or real thought constrained in the depths of his soul, which was his unscrupulous and rebellious side. Baoyu defame the buddhist monk and slander backward tradition, according to what Xi Ren said, he is speaking without taboo.The freedom and kicking over the traces of this character are also men's liberation's ideal in mind.

He is a psychopath and intersex. "from a psychological point of view, personality perversion refers to the individual psychological state of" deviation from the norm", "deviation from normality" Woolf's novel Orlando is an ideal model for his "bisexuality" and pluralism: the protagonist Orlando has undergone a history of more than four hundred years from the renaissance to the twentieth century. From an extraordinary teenager to a beautiful young woman, finally he completed the long poem from the sixteenth century, and gave birth to a son.It can transform Jia Baoyu's mentality, deviation from the norms of personality and normalcy with each other, what is The most prominent is that in his words, deeds, personality, psychology and other aspects of the feminine, it can be thought like this, Jia Baoyu is a feminized or semi-feminine male character.Not only the preference changed, but also the communicative circle were very different from men at the time, he was all day in the Grand View Garden, wanted to create a world within girls. He is the only male in this free daughter's country. He let him in this world, a gentleman, or, at times, a gentle and sentimental Knight but a supreme ruler. This abnormal psychology prompted Jia Baoyu in his character is lack of masculine masculinity, which should be more showed the feminine features, but he expressed more felinities. He soon coincides with the hearts of her daughter's emotional. Baoyu's daughter-like emotion can be called "sexual inversion" by psychology, because "sexual inversion is more like the opposite sex in the third sexuality."" Bisexuality " combined "Masculinity" with "femininity". Therefore, it is not hard to understand that Jia Baoyu has both the "masculinity" of daughters and the "femininity" of gentleness and delicateness. Cleverly designed the content of psychology point of view, and exploration of the human heart in the works, but unconsciously also blend in their own unconscious. 'Personality' is also called character, refers to the sum of the individual psychological characteristics, 'abnormal personality' also known as personality disorders, personality disorders, personality disorders, refers to the chapter or boyhood, and lasting life Significantly deviated from the normal personality. Deformity and deviation of this personality development, the performance of a long-lasting behavior of maladaptation. 


\section{Conclusion}

To make a more in-depth and more concrete exposition of Jia Baoyu's character, it is inseparable from a various of comprehensive and systematic discussion on the multiple psychological reasons for the formation of this character. Although Jia Baoyu was not accepted and accommodated by the society at that time, Jia Baoyu is mischievous and disdains study, romantic and affectionate, antagonistic and abnormal in psychology, from these psychologicals to see his character on the anti-era, all kinds of his characters extremely reflect the characteristics of the times. In general, Jia Baoyu is a traitor to feudal society.

\section{References}

[1]. Cao Xueqin, Gao E. A Dream of Red Mansion[M]. Beijing: The People's Literature Publishing House, 1974

[2]. Du Jinghua, On Cao Xueqin's Realism Principles (Northern Studies), 1981 the fifth period

[3]. Frank Goblet writes, Lu Ming, Chen Hongwen translate, Third Thought - Maslow Psychology, Shanghai: Shanghai Translation Publishing House, 2006 edition

[4]. Fu Shouxiang From the Perspective of Feminism inDream of Red Mansions - On the "Intercourse Temperament" of Wang Xi - feng and Jia Baoyu

[5]. Hao Qi, The Interpretation of Personality by Mythical Stories - An Analysis of the Personality of Jia Baoyu (Suzhou University, Suzhou 215000, China)

[6]. He Keying, An Analysis of the Multiplicity of Jia Baoyu 's Character, Audio - visual Education Center of Shangqiu Polytechnic

[7]. Li Chen Dong, The Dream of Red Mansions in Art Value (" Guo Wen Wen Zhou Bao "Volume XI, forty-seventh period, November 26, 1934 edition; forty-eighth period, December 2 edition)

[8]. Mike Featherstone, Digestion Culture - A Globalization, Postmodernism and Identity [M]. Yang Yudong translates. Beijing. Peking University Publishing House .2009.1

[9]. Peng Danling, Talking about Youth Rebellious Psychology, Beijing Normal University Press

[10]. Teng Fu, Ma Yifu and his Great Era, Lujiang Publishing House, May, 2015 